\title{
ENGINEERING GRADUATE ATTRIBUTES EXHIBITED BY HIGH SCHOOL STUDENTS
}

\author{
Allison Chong, M.A.Sc (Candidate) and David S. Strong, Professor \& NSERC Chair in Design Engineering \\ Faculty of Engineering and Applied Science, Queen's University, Ontario Canada \\ allison.chong@queensu.ca | strongd@queensu.ca
}

\begin{abstract}
Awareness and knowledge of both the engineering profession and engineering education programming is important for students in high school because strategic course choices must be made for students to qualify for university enrolment. This paper, a work-in-progress of a larger study, uses a qualitative analysis framed by the CEAB Graduate Attributes to gain insight into how teachers identify students who could become engineers. Participants clearly identified traits that describe the Knowledge Base attribute. Many participants identified other traits that described how students work; these did not fit easily within one attribute. The one attribute that was notably absent was Design.

The findings describe that participants had a partial idea of the traits that would describe a potential engineer. This gap in knowledge supports work to develop a complete idea of the engineering profession at the high school level to ensure students can make informed course selection decisions and, in turn, career decisions.
\end{abstract}

Keywords: high school, career advising, engineering traits, engineering education, outreach

\section{INTRODUCTION}

Early in high school, students are expected to make course selections that could limit what senior level courses they can take. Students choose the subject and the level of study for their core and elective courses. Without the appropriate level of study, students risk eliminating options for post-secondary study, especially programs with many and specific course pre-requisites, such as engineering programs. It is important that high school students have access to information to make informed decisions about course selection and career options. While there are many opportunities for adolescents to learn about engineering (e.g. specialized camps, outreach programs, family members, etc.) not all of these resources are commonly accessible to all students. The resources available within a high school (e.g. personnel, documents, etc.) are considered equally accessible to high school students. The resources external to the ones in the high school system are out of the scope for this research.

The focus of the overall study is to learn from individuals within high schools who advise students on post-secondary educational options and career paths. This paper is a subset of the comprehensive investigation being conducted into the advising experiences and knowledge of engineering held by subject teachers and guidance counsellors. In their classes, mathematics and science teachers interact with a large number of potential future engineering students. Additionally, among the responsibilities of guidance counsellors in Ontario, is supporting a student's career development [1].

Munro and Elsom showed that while students consider science teachers as career resources, those teachers often do not consider themselves resources for information on science-based careers. The other individuals that participated in the study were career advisers (a UKspecific position). One career adviser described that in "working in a target-driven environment... it is not timeefficient to study careers we are never asked about by pupils. We see... very few who want to do engineering." The report suggests that these individuals may not be prepared to provide career advice as they either do not have the time to learn about all the possible career options, or do not see themselves as resources [2].

It is important to learn how teachers and guidance counsellors interact with students in formal and informal career advising scenarios to gain insight into effective practices and common challenges they encounter. There is little published information as to their knowledge base for careers advice. Subject teachers and guidance counsellors are generally accessible to all students in high school, including those who are considering and could be considering engineering. This research aims to identify how to best support these points of contact in ensuring students have the required and correct information to make informed decisions. 


\subsection{Purpose of Research}

It has been shown that students struggle to make thoughtful academic decisions. In the selection of a postsecondary major, Pizzolato has shown that these decisions may be based on inappropriate or inadequate information [3]. The overarching goal of this research is to ensure that students with the appropriate qualifications, potential and interest have the necessary knowledge to consider engineering as a profession, and in turn are able to pursue the necessary high school pathway to apply to engineering schools. Two research questions were developed to guide the study design:

1. How do students use the resources available to them to learn about careers and the required educational training for these careers?

2. How do teachers and counsellors apply their knowledge of engineering when advising students on engineering programs and career paths?

This paper is focused on responses from participants of this larger study. The topics being explored in this paper are:

1. How are the potential engineering students identified?

2. How complete is the set of traits identified in a potential engineering student?

The analysis is framed in a comparison of the traits that the teachers identify as indicative of a student who should consider engineering, and what the Canadian Engineering Accreditation Board (CEAB) identifies as attributes required of the graduates of university engineering programs. The CEAB has identified the qualities expected of a graduating engineer that are academic requirements for an individual to become licensed as a professional engineer in Canada [4]. The graduate attributes of an accredited program are used to measure a student's acquisition of skills and knowledge. The CEAB graduate attributes, listed without description for brevity, are:

1. A knowledge base for engineering,

2. Problem analysis,

3. Investigation,

4. Design,

5. Use of engineering tools,

6. Individual and team work,

7. Communication skills,

8. Professionalism,

9. Impact of engineering on society and the environment,

10. Ethics and equity,

11. Economics and project management, and

12. Life-long learning.

While it is not expected that students enter an engineering program with these attributes, the attributes are a description of who has the potential to eventually become a professional engineer. The analysis aims to provide insight into what traits teachers identify as being important to a future engineer.

\subsection{Literature Review}

Existing research on traits typical of engineering students include a detailed literature review [5], a comparison between traits of students focused on a different area of study [6], an analysis of personality test data collected for other purposes [7], an investigation the effects of pre-collegiate engineering exposure on career pathway predictions [8], and a study on self-efficacy of engineering students [9].

To identify existing work on the measurement of characteristics of engineering students, Li [5] outlined a detailed literature review that showed that there is no universally agreed upon definition of engineering characteristics. Current research shows that different researchers have investigated specific characteristics of engineering students as it pertained to their areas of research. Li's research drew on over 20 years of engineering education research to identify three categories of characteristics:

1. External characteristics are defined as engineering-related properties of the community where the student is located. Students are unable to change these characteristics through 'personal endeavour'. Examples of these include adult influences, institutional environment and average income of engineers.

2. Internal characteristics are further broken down into cognitive and affective characteristics. Cognitive characteristics include high school grades (particularly mathematics), learning style, and writing abilities; they will influence the student's potential academic performance in engineering. Affective characteristics will potentially influence the motivation to succeed, and attitude towards engineering education.

3. Demographic characteristics include factors such as age, gender, race, socio-economic status. Sometimes these characteristics fit into the previous two categories.

A 2002 Belgian study [6] used a Five-Factor Model as a framework to describe personality characteristics of medical students and to understand if these traits relate to academic success. Students from seven other academic majors, including engineering, also participated in the study to serve as a comparison of what traits are typical of medical students. The findings led to recommendations 
that a personality assessment would be a useful tool to assist in medical student guidance and counselling, rather than for selection into the program.

As of 2007, the French engineering school, Telecom Bretagne-a three-year Master of Engineering curriculum, has incorporated sessions and tools that align with the CDIO (Conceive-Design-Implement-Operate) syllabus; one of the tools introduced in every year is a noncompulsory personality test. The goal of the personality test was to assist students in self-reflection to help prepare for the job search and workplace. The study performed in 2012 by Rouvaise and Chelin [7], proposed a hypothesis: "[there] exists a specific profile of engineering students". They analyzed the personality test to challenge the statement. The test asked over 200 students to respond to questions that posed two statements (e.g. "I pay close attention to details vs. I often make compromises") by selecting the one that most accurately described them. The personality analysis was based on 12 facets of human character. Very few students reached extremes regarding their personality traits, meaning that there was a fairly general profile of an engineering student at that school.

A study from 2010 [8], with a nationally representative sample of over 10,000 US high school students, utilized three waves of data collected through inschool surveys, in-home interviews, parent surveys and school administrator surveys. The study questioned if there was a combination of variables (preparation, motivation, and exposure) that contributed to the decision to study majors leading to engineering-related careers. The study looked at the relationship between preparation, motivation and exposure to engineering learning experiences. The study found significant early participation in STEM, in both formal and informal learning experiences, contributes to attracting students to particular career pathways. Additionally, it recommended that exposure to engineering fundamentals in primary and secondary school curricula would be effective to acquaint many students with the engineering field.

A study in 2011 [9], conducted at Colorado State University, investigated whether certain K-12 exposures to engineering led to higher self-efficacy in university engineering students. The study found that, generally, more exposure to pre-collegiate engineering content was associated with higher self-efficacy in engineering. Participation in pre-engineering and technology classes led to higher self-efficacy and as a result led to better performance and persistence in a university engineering program. Informal experiences (e.g. hobbies) that led to higher self-efficacy had common attributes, including: self-motivation, use of problem-solving strategies, handson application of complex subject matter, use of computer applications, and immediate feedback on success of effort.

This literature outlines that direct investigation into perceived engineering traits at a high school level will provide additional insight to the current retrospectives and studies with a non-engineering focus.

\section{STUDY DESIGN}

According to the Ontario Universities' Application Centre, the majority of potential applications to an Ontario university engineering program are from an Ontario high school (at the time of writing, this was approximately $71 \%$ ) [10-12]. As a result, the setting of this study was the Ontario high school environment common to many potential applicants to a university engineering program. Based on Munro and Elsom's study and additional insight into the Ontario high school curricular course structure, Grade 12 mathematics and science teachers, Grade 10 careers teachers, and guidance counsellors were identified as participants for this study.

As an application to university engineering programs in Ontario requires mathematics and science prerequisites, it is expected that these Grade 12 subject teachers will have interacted with many students who did, should, or are pursuing an engineering education. Additionally, teachers of the mandatory Grade 10 Careers course interact with and guide students through self-discovery and career exploration.

Although it varies school-to-school, there is often a program in place where all students are required to meet with their assigned guidance counsellor at least once during high school, with the option of additional selfbooked appointments. For this reason, guidance counsellors were also invited to participate. In some participant cases, guidance counsellors held additional roles at the school, including but not limited to student success teachers and a Grade12 biology teacher.

\subsection{Methodology}

A phenomenological approach was used as a basis for the research design. This qualitative approach investigates an individual's or a group's perception of reality as they understand it. The phenomenon in this study is how science, mathematics and career teachers, as well as guidance counsellors, guide and inform students about engineering education and careers in engineering. A protocol was designed to encourage participants to talk about their experiences interacting with students in career exploration or advising scenarios. Patton recommends capturing this experience and focusing on how individuals who have lived this experience firsthand perceive, describe, remember and make sense of it [13]. The approach will provide insight into how the individuals identify students who could become engineers. 


\subsection{Methods}

The larger study utilizes participants with varying educational and occupational backgrounds, and all currently teach Grade 12 mathematics, or Grade 12 sciences, Grade 10 careers, or are a guidance counsellor. These individuals were surveyed using a mix of multichoice and short answer questions about their educational and occupational background, and about the nature of their advising interactions with students. The survey was designed to assist in participant selection for an individual follow-up interview, using the maximum variation purposeful sampling technique. This sampling technique was selected to ensure the study captured information rich descriptions from participants with a broad range of backgrounds.

Seventeen participants from three schools in Southern Ontario answered the short participant selection survey. Nine of them volunteered and participated in an individual follow-up interview. They were asked to select a quiet location in the school where the interview could take place; most selected an office or a classroom. The interview protocol was designed to facilitate a semistructured interview consisting of five open-ended questions with specific goals and intents planned. The interviews took on average 30 minutes.

The data used in this paper was the final question posed in the interview. The question asked participants to identify students' traits that would lead the participant to consider recommending that the student learn more about engineering.

\section{ANALYSIS}

As a qualitative study, the analysis is a result of the researcher's interpretation of the data, and in this case, the interpretation of the CEAB graduate attributes [4]. Coding of the participant data was completed while maintaining the context of their statements. Open-coding was performed on the transcribed fifth question from the interview. NVivo ${ }^{\mathrm{TM}}$ software was used to organize the coding process. Once these codes were generated, they were organized according to the graduate attribute they were interpreted to be describing.

\section{RESEARCH FINDINGS}

While the final question was intended to get participants talking about traits that they recognize in students who should consider engineering, additional commonalities in responses arose. A few participants immediately identified students who they didn't think would be suited for engineering. Many participants recognized the limit of their knowledge or their bias upfront, while still responding honestly to the question.

\subsection{Match of Graduate Attributes}

The most commonly identified attribute was $A$ Knowledge Base for Engineering. Many participants identified the need for mathematics, science - specifically physics and chemistry, in a variety of capacities. The description of subject knowledge included strength of understanding, consistent performance, and enjoyment in the subject. Consistency, academic performance trends, and early recognition of strength in a subject were additional ideas that were expressed by teachers as indicators of students who could become engineers.

Individual and Team Work was identified by the work habits that participants observed. The ability to focus on a problem, and strong work ethic were two examples given. Additionally, one participant mentioned that students who were heavily involved in extracurricular activities (e.g.: "point guard on the basketball team or lead in the school play") were frequently students who went into engineering.

Indicators of Professionalism or Impact on Society were identified as consistently accurate student work and its relation to the participant's recognition of the complexity of the engineering profession and the importance of accuracy in it (e.g. that calculations lead to correct sizing of a bridge).

In describing Problem Analysis, participants expressed ideas of how students approach problems and their drive to determine the correct solution.

Investigation and Life-long Learning ideas were interpreted similarly in more general terms, such as a curiosity in wanting to learn and questioning information given to them.

The only mention of Communication Skills was by a teacher with a science background who recalled a course she took that instructed how to "write for science". She identified that students who "innately can write well and get their scientific ideas across well, and the precision there too" would stand out to her as ones who would excel in university science and engineering. She highlighted that writing for science was very different from Writer's Craft (an elective Grade 12 university level English credit).

\subsection{Non-engineer Identification}

Some participants stated that it was easier to spot a student for whom they would not recommend engineering. Their examples of this were students who were unorganized or continuously struggled in mathematics. Two participants with guidance backgrounds commented on a trend that the students they would identify who were 
not suitable for engineering were the ones with the strongest marks in mathematics and physics courses. One clarified that the strongest performers often went into pure mathematics or sciences. The other mentioned that future engineering students had "some strength in math and physics" but were often heavily involved in extracurricular activities. A different participant described her bias as associating "out-of-the-box thinkers" as future researchers who needed to "dream of possibilities". Most participants recognized, as a disclaimer, that they had biases and that there were things that students could change (e.g. work ethic, or grades) if a student truly wanted to pursue engineering.

\subsection{Self-recognized Limits of Participants}

Participants identified personal limits in knowledge and/or in their perception of the advising scope that was within the responsibilities of their educational role. Many of the participants were honest and forward in prefacing their answer, saying things like: "Not being an engineer myself, the only thing I would know, or that I think I know, and I could be wrong..." or, "I know, like for example, I know that there is chemical engineering and a huge number of things but what those are? I have no idea, and what's involved in one versus the other, I have no idea." One acknowledged a personal bias in identifying a student who could become an engineer as one that reminded her of her brother who is an engineer.

Hesitation was apparent in a few cases in which the participant was a bit reluctant in providing concrete responses. Three identified that in their role they didn't see it as their responsibility to tell students what to pursue, stating that they would encourage students to learn more but would, as one stated, "try really hard not to impose what I think might work for them". A guidance counsellor identified the perceived limit to her role by questioning, "who am I to say that 'you can't be successful at this', and to say 'you won't make it as this'. But if there is concrete evidence there, like if they're not in the right pathway, they're going to have to do something".

\section{DISCUSSION}

The analysis uncovered that participants identified traits that could map to 8 out of 12 of the graduate attributes. Apart from the comments regarding academic strength in mathematics, physics, chemistry or science overall, the other traits that were identified were not as straightforward to categorize. While some traits could fit within many of the attributes or were quite general, none of the traits identified were significantly incorrect. The attributes missing were: Design, Use of Engineering
Tools, Ethics and Equity, and Economics and Project Management.

There were ideas around how a student acquires and applies knowledge that would fit loosely, at best, in Use of Engineering Tools. The absence of this attribute, Ethics and Equity, and Economics and Project Management may be of less concern as they are more specific to the profession of engineering and are potentially out of scope of the current high school curriculum. However, the most significant absence is of the Design attribute. The only mention of creativity (which is typically identified as a key element of engineering design [14], [15]) was from the participant that identified that a creative dreamer should pursue research. This analysis shows that there are common ideas about the engineering profession; however, there are also areas that require visibility and correction.

Apart from the attributes, the other themes that arose in the analysis indicated that participants recognized that they lacked knowledge to make educated recommendations for students, and some were much more ready to identify students who would not be suitable. For participants who lacked confidence in identifying engineering traits, they disclosed that they often give students a starting point (e.g. identifying there are different disciplines of engineering), then recommended individual research or to turn to guidance for information. This lack of knowledge often was related to a lack of confidence in their knowledge and a fear of giving a student incorrect information. The identification of students who probably would not be a good fit in an engineering program was often tied to lack of organization and work ethic, in addition to academic weaknesses in mathematics and science.

While this analysis showcases that collectively participants were able to recognize many traits that would be an asset to a professional engineer, the fact that the traits only loosely mapped to an incomplete list of attributes means that participants do not have a strong grasp of what a professional engineer is and/or does.

\section{CONCLUSIONS}

A larger research study aims to learn about the resources used by students to learn about post-secondary opportunities, and the resources used by teachers and guidance counsellors support students in this discovery. This paper focuses on the analysis of the responses to a question posed to teacher and guidance counsellor interview participants about what traits they would recognize in a student who should consider engineering. An open-coding analysis was performed on the data collected from this question and the traits identified were compared with the CEAB graduate attributes. The analysis revealed that many participants recognize that a 
knowledge base in scientific and mathematic concepts was important, a strong and focused work ethic is required, and that accuracy is important in the profession. It also revealed that creativity or aptitude for design was misplaced or lacking in the participants' ideas about engineering. Additionally, it was common for participants to add a disclaimer to their responses that identified their bias, lack of knowledge, or lack of confidence in their knowledge about engineering or how to identify potential engineers.

Ideally, those who support students in high school (teachers and guidance counsellors) have a grasp of how to advise students presenting an interest in pursuing engineering, and how to identify a student who should consider the profession. The findings presented inform how to ensure teachers are able to confidently describe the engineering profession. Many identified a trait related to Attribute 1 (students' academic subject strength) and another between 2 and 7 (how students do and approach work); few identified more than two traits. Additionally, few identified any traits related to the professional responsibilities (described in 8 to 11 ) required of a professional engineer.

In addition to clearly understanding the frequently identified attributes, perhaps it is overly optimistic to expect teachers and guidance counsellors to understand the specific professional responsibilities. It may be more reasonable to expect that these individuals have the broader idea that engineering is a complex profession with design as a core element, and an obligation to protecting the public and public interest in their work.

This analysis provides insight into what is known about engineering, and what information is still needed. The larger study being conducted on engineering career resources in high schools will present additional ideas on the information needed, and how to disseminate this information.

\section{Acknowledgements}

This paper, and the larger research study, would not have been possible without funding from NSERC through the Chairs in Design Engineering program, support from the community of engineering education researchers at Queen's, and the participation of the schools, students, teachers, and guidance counsellors.

\section{References}

[1] Ontario School Counsellors' Association, "Role of the Guidance Counsellor.”

[2] M. Munro and D. Elsom, "Choosing Science at 16: The Influence of Science Teachers and Career Advisers on Students' Decisions about Science Subjects and Science and Technology Careers.," 2000.
[3] J. E. Pizzolato, “Advisor, teacher, partner: Using the learning partnerships model to reshape academic advising," About Campus, vol. 13, pp. 18-25, 2008.

[4] Engineers Canada, "Accreditation Criteria and Guidelines,” Ottawa, 2014.

[5] Q. Li, "Measurement of Characteristics of Engineering Students : What Has Been Done and What Needs to Be Done?," p. 10, 2007.

[6] F. Lievens, P. Coetsier, F. De Fruyt, and J. De Maeseneer, "Medical students' personality characteristics and academic performance: A five-factor model perspective," Med. Educ., vol. 36, no. 11, pp. 1050-1056, 2002.

[7] S. Rouvrais, N. Chelin, T. Bretagne, and I. Minestelecom, "Introducing Personality Tests to Clarify Engineering Student Self-Perception and Demystify Recruitment Procedures : Quantitative and Qualitative Results," in 8th International CDIO Concerence, 2012.

[8] D. N. Williams and M. A. Gottfried, "Who Chooses the E in STEM ?," in EE2010: Inspiring the next generation of engineers, 2010, pp. 1-20.

[9] T. D. Fantz, T. J. Siller, and M. A. Demiranda, "PreCollegiate Factors Influencing the Self-Efficacy of Engineering Students," J. Eng. Educ., vol. 100, no. 3, pp. 604-623, Jul. 2011.

[10] Ontario Universities' Applications Centre, "Undergraduate Application Statistics - April 2015," 2015. [Online]. Available:

http://www.ouac.on.ca/statistics/ugrad-appstats/uapp_apr/.

[11] Ontario Universities' Applications Centre, "Secondary School (OUAC101) Monthly Application Statistics (by Program)," 2015.

[12] Ontario Universities' Applications Centre, 'Nonsecondary (OUAC105) Monthly Application Statistics," 2015.

[13] M. Q. Patton, Qualitative research and evaluation methods, 3rd ed. Thousand Oaks: Sage Publications, 2002.

[14] T. Howard, S. Culley, and E. Dekoninck, "Creativity in the Engineering Design Process," Sci. York, no. August, pp. 1-12, 2007.

A. Chakrabarti, "Defining and Supporting Design Creativity," DS 36: Proceedings DESIGN 2006, the 9th International Design Conference. pp. 479-486, 2006. 